lành tính, giúp rút ngắn thời gian nằm viện, đem lại hiệu quả thẩm mỹ cao. Bệnh viện Ung Bướu Nghệ An là một trong những bệnh viện tuyến tỉnh đâu tiên thực hiện thành công kỹ thuật này. Kỹ thuật này nên được phát triển và mở rộng để bệnh nhân bệnh lý tuyến vú có thêm một lựa chọn bên cạnh mổ hở. Trong tương lai, VABBB cân được áp dụng nhiều hơn để sinh thiết chẩn đoán các trường hợp nghi ngờ ung thư ở các tổn thương nhỏ hoặc các tổn thương không sờ thấy.

\section{TÀI LIÊU THAM KHẢO}

1. Huỳ̀nh Quang Khánh (2018). Kết quả chẩn đoán và điêuu trị tổn thương tuyến vú bằng thiết bị sinh thiết vú có hỗ trợ hút chân không dưới hướng dẫn siêu âm. Ung thư học Việt Nam, số 4-2018

2. Trân Viêtt Thế Phương và CS (2018). Sinh thiết vú có hồ trợ hút chân không (VABB) dưới hướng dẫn của siêu âm trong chẩn đoán và điều trị tổn thương vú. Ung thư học Việt Nam, số 4-2018.

3. Park HL, Kang SS, Kim DY, et al. "Is surgical excision necessary for a benign phyllodes tumor of the breast diagnosed and excised by ultrasound- guided vacuum assisted biopsy device (mammotome)?" ] Korean Surg Soc 2007; 73: 198 -203

4. Karol P, Dawid M, Piotr N, "Vacuum assisted core-needle biopsy as a diagnostic and therapeutic method in lesions radiologically suspicious of breast fibroadenoma", Reports of practical oncology and radiotherapy. 2011 (16),32-35.

5. Fu SM, Wang $X M$, Yin CY, Song Hui, "Effectiveness of hemostasis with Foley catheter after vacuum- assisted breast biopsy", Journal of Thoracic Disease, 2015, 7(7), 1213-1220.

6. Lee SH, Kim EK, Kim MJ, Moon HJ, Yoon JH, "Vacuum assisted breast biopsy under ultrasonographic guidance: analysis of a 10 year experience", ultrasonography, 2014 (33), 259 -266.

\title{
NGHIÊN CỨU ĐẶC ĐIỂM HÌNH ẢNH CộNG HƯỞNG TỪ U TRONG ỐNG SỐNG
}

\author{
Trịnh Anh Tuấn ${ }^{1}$, Nguyễn Đình Minh ${ }^{1}$, Nguyễn Duy Hùng ${ }^{1,2}$
}

\section{TÓM TẮT}

Mục tiêu: Nghiên cứu nhằm mô tả các đặc điểm của các u trong ống sống (UTOS) trên cộng hưởng từ (CHT). Đối tượng và phương pháp: Nghiên cứu mô tả cắt ngang với 49 bênh nhân UTOS được chup $\mathrm{CHT}$ cột sống và phẫu thuật tại bệnh viện Việt Đưúc từ tháng 7/2019 đên 9/2020. Kêt quả: UTOScó độ tuổi

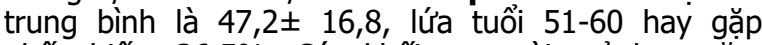
nhất,chiếm 26,5\%. Các khối u ngoài tuỷ hay găp chiếm $87,8 \%$. Loại u hay gặp nhất là u bao dây thần kinh (Neurinoma) chiếm $38,8 \%$ và u màng tuỷ (Meningioma) với $20,4 \%$. Trên CHT, vị trí u hay gặp nhất là vùng cột sống ngực với $40,8 \%$. Kích thước trung bình của u là $35,9 \pm 33,5 \mathrm{~mm}$. Có $95,9 \%$ u có ranh giới rõ, 87,8\% u chèn ép tủy sống và hoặc rễ thần kinh ngang mức. Khối u đồng tín hiệu trên T1W là $51 \%$ và u tăng tín hiệu trên $\mathrm{T} 2 \mathrm{~W}$ là $40,8 \%$, có $93,9 \%$ khối u ngấm thuốc sau tiêm. Kết luận. CHT có giá trị trong phát triện vị trí, kích thước, mức độ chèn ép thần kinh và gợi ýn nguồn gốc mô bệnh học của UTOS.

Tiư khoá: u trong ống sống, cộng hưởng từ, u bao dây thần kinh, u màng tuỳ.

\section{SUMMARY \\ MAGNETIC RESONANCE IMAGING FEATURES OF SPINAL TUMORS}

\footnotetext{
${ }^{1}$ Bệnh viện Hữu nghi Việt Đức

${ }^{2}$ Trường Đai hoc y Hà Nối

Chịu trách nhiệm chính: Trịnh Anh Tuấn

Email: anhtuanhmu31093@gmail.com

Ngày nhận bài: 23.10.2020

Ngày phản biên khoa học: 17.12.2020

Ngày duyệt bài: 8.12 .2020
}

Objects: The aim of this study is to describe the characteristics of spinal tumors on magnetic resonance imaging (MRI). Materials and Methods: A descriptive cross-sectional study on 49 patients of spinal tumors was documented with MRI and surgical treatment at Viet Duc University Hospital from July, 2019 to September, 2020. Results: The study showed the average age of patients was $47,2 \pm 16,8$, out of which the proportion of the age between 51 and 60 was highest, at 26,5\%. Extramedullary and intramedullary tumors comprised $87,8 \%$ and $12,8 \%$ of all cases, respectively. The common tumors were neurinoma $(38,8 \%)$ and meningioma $(20,4 \%)$. On MRI, the most common location of tumors is thoracic spine with $40,8 \%$ of cases. The average tumor size was $35,9 \pm 33,5 \mathrm{~mm}$. There were $95,9 \%$ of tumors having well-defined boundaries and $87,8 \%$ of tumors extended into spinal cord and/or spinal nerve roots at the same level. Tumors with isointense signal on T1W comprised $51 \%$, with hyperintensity on T2-weighted MRI was $40,8 \%$. There were $93,9 \%$ of tumors enhanced on postgadolinium. Conclusion, MRI plays an important role in identifying the anatomic location, the size, the degree of neural compression and suggesting histopathology of spinal tumors.

Keyword: spinal tumors, magnetic resonance imaging (MRI), neurinoma, meningioma.

\section{I. ĐẶT VẤN ĐỀ}

U trong ống sống (UTOS) là bệnh lý ít gặp, chiếm tỉ lệ từ $5-10 \%$ các khối u của hệ thần kinh trung ương. Dựa theo khoang giải phẫu, các UTOS được chia làm hai nhóm chính gồm UTOSngoài tuỷ và u trong tuỷ sống, trong đó các 
khối u ngoài tuỷ chiếm tỉ lệ 70-80\%[1]. Các UTOS đa phần lành tính và tiến triển chậm nhưng do ống sống là khoang giải phẫu chật hẹp nên khối u sớm gây hiệu ứng chèn ép tuỳ sống và các cấu trúc lân cận, do đó nếu không được điều trị kịp thời bệnh nhân có thể dẫn tới tàn phế, thậm chí tử vong [2]

Cộng hưởng từ (CHT) là lựa chọn hàng đầu trong chẩn đoán các khối UTOS do có độ phân giải cao các cấu trúc mô mềm cũng như khả năng tạo ảnh đa mặt phẳng so với các phương pháp khác góp phần nâng cao chất lượng chẩn đoán [3].

Các nghiên cứu tiến hành trước đây đều cho thấycác UTOS nếu được phẫu thuật sớm sẽ mang lại kết quả điều trị tốt. Đo đó $\mathrm{CHT}$ đóng vai trò rất hết sức quan trong trong phát hiện sớm các UTOS và góp phần đề ra chiển lược điều trị thích hợp nhằm nâng cao chất lượng cuộc sống cho các bệnh nhân (BN) sau điều trị. Tại Việt Nam các nghiên cứu về CHT các UTOS chưa nhiều và được tiến hành trên các máy $\mathrm{CHT}$ thế hệ cũ, độ phân giải còn hạn chế [4]. Do vậy, chúng tôi tiến hành nghiên cứu này nhằm "Mồ tả đặc điểm hinh ảnh cộng hưởng của u trong ống sốnghay gặp".

\section{II. ĐỐI TƯợNG VÀ PHƯƠNG PHÁP NGHIÊN CỨU}

2.1 Đổi tượng nghiên cứu. Bao gồm $49 \mathrm{BN}$ chẩn đoán UTOS trên $\mathrm{CHT}$ được điều trị bằng phẫu thuật tại bệnh viện hữu nghị Việt Đức từ tháng $7 / 2019$ đến 9/2020.
Tiêu chuân lựa chon: BN tuổi từ 18 trở lên, được chụp $\mathrm{CHT}$ và chẩn đoán là UTOS, được phấu thuật và có kết quả Giải phẫu bệnh.

Tiêu chuẩn loại trừ: BN không thỏa mãn tiêu chuẩn lựa chọn.

2.2 Phương pháp nghiên cứu:

Phương pháp nghiên cứu: Mô tả cắt ngang

Phương tiện nghiên cứu:

- Máy cộng hưởng từ 1.5 Tesla Avanto của hãng Siemens (Đức), máy cộng hưởng từ 1.5 Tesla của hãng Phillips (Hà Lan) hoặc máy chụp 3.0 Tesla SIGNA Pioneer của hãng GE healthcare (Mỹ).

- Hệ thống lưu trữ hình ảnh PACS của INFINITI (Hàn Quốc) hoặc phim chụp CHT cột sống.

2.3. Thiết kế nghiên cứu: Nghiên cứu mô tả phim chụp $\mathrm{CHT}$ của các bệnh nhân được chẩn đoán là UTOS về các đặc điểm:

+ Vị trí u trên mặt phẳng nằm ngang và dọc theo cột sống.

+ Tín hiệu khối u trên các chuỗi xung T1W,

T2W, T1 sau tiêm đối quang.

+ Sự thay đổi các cấu trúc xung quanh khối u.

Phân tích và xử lý số liệubằng phần mềm SPSS 20.0 (Chicago, IL, Mỹ).

\section{KẾT QUẢ NGHIÊN CứU}

\section{1. Đăc điểm chung}

+ Nghiên cứu trên 49 BN (32 nam và 17 nũ) tỷ lệ nam: nữ là $1,88: 1$

+ Tuổi trung bình là 47,2 $\pm 16,8$ trong đó trẻ nhất là 12 tuổi, già nhất là 83 tuổi, lứa tuổi hay gặp là 51-60 chiếm 26,5\%.

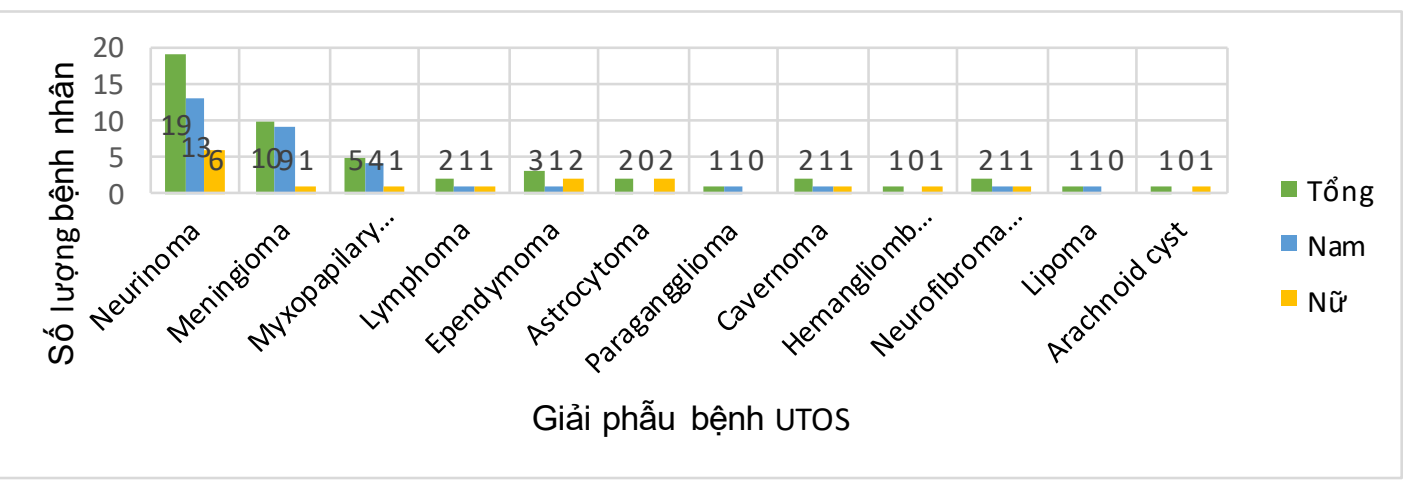

Biểu đồ 1: Phân bố UTOS theo mô bệnh học và giới tính (n=49)

+ Hay gặp nhất là u bao rễ thần kinh (Neurinoma) với 19/49 (38.8\%), tiếp theo là u màng não tủy (Mengioma)với 10/49 (20,4\%), u màng ống nội tuỷ nhú nhầy (Myxopapillary Ependymoma) và $u$ màng ống nội tuỷ (Ependymoma) ít gặp, chiếm $<10 \%$.

\section{2. Đặc điểm cộng hưởng từ UTOS}

\section{1. Đăc điểm vị trí của UTOS}

+ Các UTOS hay gặp ở tầng ngực với 20/49 $(40,8 \%)$, tiếp theo là thắt lưng với $14 / 49$ $(28,5 \%)$, tầng cổ ít gặp hơn với tỷ lệ $<10 \%$ (biểu đồ 2).

+ CácUTOS ngoài tuỷ hay gặp nhất chiếm $43 / 49(87,8 \%)$, u trong tuỷ chỉ gặp 6/49 $(12,2 \%)(p<0,05)$. 


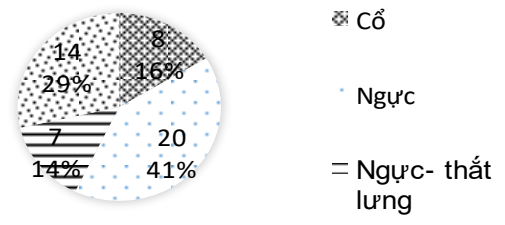

Biểu đồ 2: Phân bố UTOS theo vị trí phân bố tầng côt sống $(n=49)$

\section{2. Đặc điểm kích thước và liên quan của khối u.}

+ Kích thước trung bình (KTTB) của khối u theo trục lớn nhất là $35.9 \pm 33.5 \mathrm{~mm}$, trong đó u nhỏ nhất là $8 \mathrm{~mm}$ và lớn nhất là $210 \mathrm{~mm}$. KTTB của u bao thần kinh và u màng não tủy lần lượt là $26.2 \pm 12.8 \mathrm{~mm}$ và $19 \pm 11.8 \mathrm{~mm}$.

+ Ranh giới khối u rõ là 47/49 (95.9\%), ranh giới không rõ là 2/49 (4.1\%) và đều là Lymphoma.

+ Dấu hiệu chèn ép tủy sống hoặc rễ thần kinh đuôi ngựa ngang mức gặp trong 43/49 $(87,8 \%)$ trường hợp.

2.3. Đặc điểm tín hiệu của UTOS trên CHT.

+ Các khối u bao thần kinh thường đồng tín hiệu trên $T 1 W$ với $13 / 19(68,4 \%)$ và tăng tín hiệu trên T2W với 11/19 (57,9\%). Khối u màng não tủy thường đồng tín hiệu trên T1W với $5 / 10$ (50\%) và đồng hoặc giảm tín hiệu trên T2W với $3 / 10(30 \%)$.

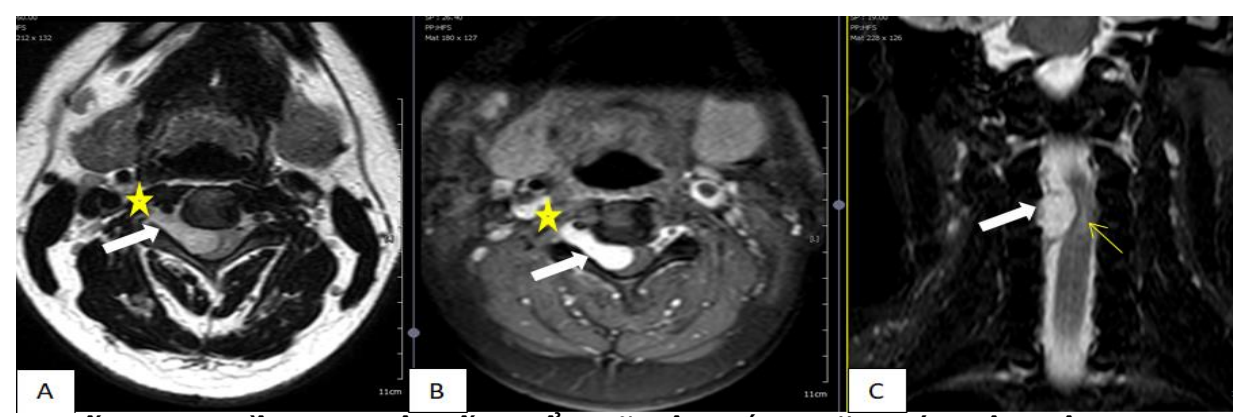

Hình 1: khối u bao thần kinh cột sống cố (mũi tên trắng) tăng tín hiệu trên T2W Axial (ảnh $A$ ), ngấm thuốc mạnh và đồng nhất trên T1Fatsat Axial sau tiêm thuốc thuốc đối quang từ (ảnh $B$ ), khối phát triển gây rộng lỗ tiếp hợp $C 3 / 4$ bên phải (hình sao ảnh $A$ và $B$ ), khối đè ép tủy cổ sang trái và gây phù tủy cổ ngang mức (mũi tên vàng) trên chuỗi xung STIR Coronal (ảnh C).

+ Tất cả các khối u bao thần kinh và u màng não tủy đều có ranh giới rõ trên hình ảnh CHT. Dấu hiệu đuôi màng cứng gặp 19/19 $(100 \%)$ các khối u bao thần kinh nhưng chỉ 5/10 (50\%) ở các khối u màng não tủy. Rộng lỗ tiếp hợp thấy ở $3 / 19(15,8 \%)$ u bao rễ thần kinh và $1 / 10$ $(10 \%)$ các khối u ngoài màng tủy.
+ Sau tiêm, có 12/19 (63,2\%) khối u bao thần kinh ngấm thuốc không đồng nhất, trong khi $9 / 10(90 \%)$ khối u màng não tủy ngấm thuốc đồng nhất $(p<0,05)$.

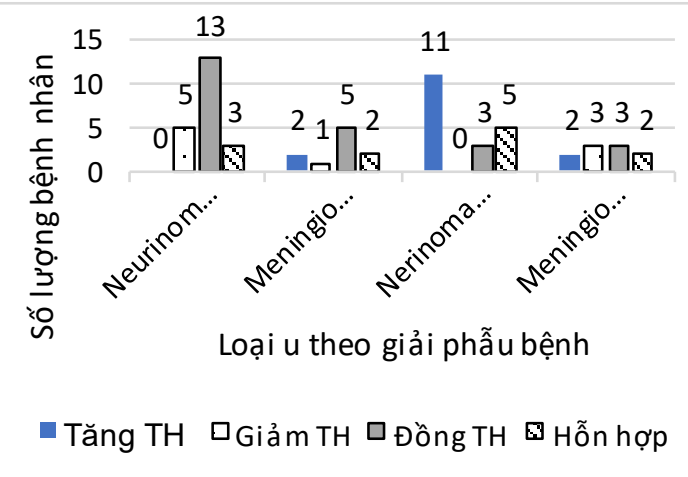

Biều đồ 3. Đặc điểm tín hiệu u bao thần kinh và u màng não tủy

Bảng 2. Đăc điểm của u bao thân kinh và u màng nã̃o tủy trên CHT

\begin{tabular}{|c|c|c|c|}
\hline $\begin{array}{c}\text { Đặc điếm } \\
\text { CHT }\end{array}$ & $\begin{array}{c}\text { U bao thân } \\
\text { kinh }\end{array}$ & $\begin{array}{c}\text { U màng } \\
\text { não tủy }\end{array}$ \\
\hline Ranh giới & Rõ̃ & $19(100)$ & $\mathrm{n}(\%)$ \\
\hline & Không rõ & 0 & 0 \\
\hline $\begin{array}{c}\text { Đuôi màng } \\
\text { cứng }\end{array}$ & Có & $19(100)$ & $5(50 \%)$ \\
\hline $\begin{array}{c}\text { Rộng lổ liên } \\
\text { hợp }\end{array}$ & Không & 0 & $5(50 \%)$ \\
\hline & Kó & $3(15,8 \%)$ & $1(10 \%)$ \\
\hline
\end{tabular}

\section{BÀN LUÂN}

U trong ống sống là những khối u phát triển từ các thành phần trong ống sống bao gồm tuỷ sống, dây tận, rễ thần kinh, màng tuỷ... Khối u có thể lành tính hay ác tính, nguyên phát hoặc thứ phát và có thể dẫn tới những hậu quả nghiêm trọng đối với người bệnh [5]. Khi CHT 
chưa phát triển, chẩn đoáncác khối UTOS chủ yếu dựa vào $X$-quang hay cắt lớp vi tính và gặp nhiều khó khăn do không đánh giá trực tiếp được các thành phân trong u, các UTOS thường được phát hiện muộn khi đã phát triểngây chèn ép tủy sống gây nên triệu chứng lâm sàng nặng nề như liệt, rối loại đại tiểu tiện, tử vong[6]

Trong nghiên cứu của chúng tôi, UTOS hay gặp ở nam giớivới tỉ lệ nam: nữ là 1,88 . Điều này tương tựkết quả nghiên cứu của tác giả Santosh và cs trong đó nam giới chiếm $57,3 \%$, nữ giới chiếm 42,7\%[7].

Độ tuổi trung bình của UTOS trong nghiên cứu này là $47,2 \pm 16,8$ trong đó hay gặp nhất ở lứa tuổi trung niên từ 51-60 tuổi với 26,5\%. Điều này là khác biệt với nghiên của Santosh và cS trong đó lứa tuổi hay găp nhất là 41 đến 50 tuổi[7]. Như vậy, hầu hết bệnh nhân UTOS đang còn trong độ tuổi lao động, nếu không chẩn đoán sớm và điều trị kịp thời sẽ ảnh hưởng không những đến sức khỏe vá chất lượng cuộc sống của bệnh nhân mà còn ảnh hưởng đến kinh tế và hạnh phúc của gia đình của người bệnh.

Trong nghiên cứu của chúng tôi, u bao thần kinh là loại hay gặp nhất chiếm $38,7 \%$, tiếp đến là u màng não tủy chiếm 20,4\%. Các khối u nhưu màng ống nội tuỷ nhú nhầy, u hạch hayu màng nội tủy ít gặp hơn. Nghiên cứu củaDasarju hay Chungđều chỉ ra rằng $u$ bao thần kinh là hay gặp nhất trong ống sống với tỉ lệ lần lượt trong các nghiên cứu là $34,8 \%$ và $48,7 \%$ [7][8]. Nghiên của của Dasarju và cs thây rằng các khối u trong tuỷ chiếm 20\% [6]. Trong nghiên cứu của chúng tôi các khối u trong tuỷ sống chiếm $12,8 \%$. Như vậy, ubao thần kinh và u màng não tuỷ là 2 khối u ngoài tuỷ hay gặp nhất, đây là những u lành tính, do đó nếu phát hiện sớm trên $\mathrm{CHT}$ và được điều trị bằng phẫu thuật, bệnh nhân có thể khỏi bệnh hoàn toàn.

Trong nghiên cứu này, Kích thước lớn nhất trung bình trên CHT của khối UTOS là $35.9 \pm 33.5 \mathrm{~mm}$, trong đó kích thước trung bình của u bao thần kinh và u màng não tủy lần lượt là $26.2 \pm 12.8 \mathrm{~mm}$ và $19 \pm 11.8 \mathrm{~mm}$. Như vậy các khối u này có KTTB nhỏ hơn các UTOS nói chung. Bên cạnh đó, dấu hiệu chèn ép tuỷ sống hay rề thần kinh ngang mức của các khối u trong nghiên cứu của chúng tôi gặp trong $87,8 \%$ và tất cả là các đều là các khối u ngoài tuỷ sống. Điều này có thể do u bao thần kinh và u màng não tủy là các khối u ngoài tủy nên các triệu chứng chèn ép thần kinh trong ống sống sẽ tương đối sớm khiến bênh nhân đến khám và được phát hiện sớm hơn các loại UTOS khác.
Trong nghiên cứu của chúng tôi khối u đồng tín hiệu trên T1W gặp $51 \%$, tăng tín hiệu trên T2W gặp 40,8\% trường hợp. Kết quả nghiên cứu của chúng tôi tương đồng với nghiên cứu của tác giả Quiles A.M cho thấy các khối u trong ống sống đồng tín hiệu trên T1W trong $48 \%$ trường hợp, tăng tín hiệu trên T2W gặp 70,8\% [5]. Mặt khác, theo kết quả nghiên cứu thì $68,4 \%$ các khối u bao thần kinh đồng tín hiệu trên T1W và $57,9 \%$ tăng tín hiệu trên T2W. Khối u màng não tủy đồng tín hiệu trên T1W là $50 \%$ và đồng hoặc giảm tín hiệu trên T2W là $30 \%$. Như vậy, các khối UTOS đa phần đồng tín hiệu với tuỳ sống trên $T 1 W$, tăng tín hiệu trên $T 2 W$ và gân tương đương với dịch não tuỷ nên dễ bị bỏ sót nếu không tiêm thuốc đối quang từ.

Trong nghiên cứu của chúng tôi khối UTOS ngấm thuốc đối quang từ sau tiêm gặp 93,9\%. Kết qủa này tương tự trong nghiên cứu củaQuiles và cs với khối u ngấm thuốc sau tiêm chiếm 94,3\%. Mặt khác, kết quả chúng tôi nhận thấy $63,2 \%$ khối u bao thần kinh ngấm thuốc không đồng nhất, trong khi $90 \%$ khối u màng não tủy ngấm thuốc đồng nhất. Do đó khi có triệu chứng lâm sàng nghi ngờ có UTOS thì cần phải xem xét kỹ các hình ảnh CHT các chuỗi xung trước tiêm, nếu nghi ngờ thì bệnh nhân nên được tiêm thuốc đối quang từ để phát hiện khối u tốt hơn. Tính chất ngấm thuốc của các khối UTOS có thể giúp phân biệt các u bao thần kinh với u màng não tủy.

Kết quả nghiên cứu cho thây $95.9 \%$ khối u có ranh giới rõ với các cấu trúc lân cận, trong đó tất cả các khối u bao thần kinh và u màng não tủy đều có ranh giới rõ trên hình ảnh $\mathrm{CHT}$. Như vậy, xem xét kỹ hình ảnh $\mathrm{CHT}$ có giúp phẫu thuật viên đánh giá khả năng bóc tách khối u trước khi mổ, khả năng lấy bỏhoàn toàn khối u và bảo tồn các cấu trúc giải phẫu lân cận.

Trên hình ảnh $\mathrm{CHT}$, dấu hiệu đuôi màng cứng chúng tôi gặp $0 \%$ các khối u bao thần kinh nhưng gặp ở $50 \%$ ở các khối u màng não tủy. Thêm vào đó, chúng tôi thấy dấu hiệu rộng lỗ tiếp hợp hay gặp ở u bao rễ thần kinh $(15,8 \%)$ hơn là u màng não tủy (10\%). Đây cũng là những dấu hiệu quan trọng giúp phân biệt hai loại u này trên hình ảnh CHT.

\section{KẾT LUÂN}

U trong ống sống là ít gặp và đa phần lành tính, do đó nếu được phát hiện sớm và điều trị kịp thời sẽ đem lại hiệu quả tốt. Các khối u hay gặp là u bao thần kinh và u màng não tủy. Cộng hưởng từ có vai trò quan trọng giúp phát hiện 
khối u và mức độ liên quan giữa u và các cấu trúc lân cận. Các dấu hiệu trên CHT như chèn ép tủy sống, ngấm thuốc sau tiêm là những yếu tố quan trọng để phân biệt UTOS và các tổn thương khác.

\section{TÀI LIỆ THAM KHẢO}

1. K. K. Koeller and R. Y. Shih, 'Intradural Extramedullary Spinal Neoplasms: RadiologicPathologic Correlation', RadioGraphics, vol. 39, no. 2, pp. 468-490, Mar. 2019, doi:10.1148/rg. 2019180200.

2. L. L. Mechtler and $K$. Nandigam, 'Spinal Cord Tumors', Neurologic Clinics, vol. 31, no. 1, pp. 241-268, Feb. 2013, doi: 10.1016/j.ncl.2012.09.011.

3. K. Abul-Kasim, M. M. Thurnher, P. McKeever, and $\mathbf{P}$. C. Sundgren, 'Intradural spinal tumors: current classification and MRI features', Neuroradiology, vol. 50, no. 4, pp. 301-314, Apr. 2008, doi: 10.1007/s00234-007-0345-7.
4. Pham Ngọc Hoa, 'Đặc điểm hình ảnh cộng hưởng từ u tế bào schwann và u màng não trong màng cứng ngoài tủy', $Y$ học thành phố Hồ Chí Minh, 2009.

5. A. M. Quiles Granado, 'A Comprehensive Review of Intraspinal tumors: Diagnostic, classification and radio-pathologic correlation.', p. 4057 words, 2013, doi: 10.1594/ECR2013/C-2112.

6. V. K. Dasarju, S. Sree, M. S. Kikkeri, B. Shireesha, N. Pallavi, and Ch. S. Kumar, 'Magnetic Resonance Imaging in Spinal Tumors', IJCMSR, vol. 5, no. 1, Mar. 2020, doi: 10.21276/ijcmsr.2020.5.1.50

7. S. K. Panda, B. Nayak, M. Panigrahi, and P. Das, 'MRI Evaluation of Intramural Tumors of Spine in Adult and Pediatric Population- A Study at Tertiary Care Centre', p. 6.

8. J. Y. Chung, J. J. Lee, H. J. Kim, and H. Y. Seo, 'Characterization of Magnetic Resonance Images for Spinal Cord Tumors', Asian Spine J, vol. 2, no. 1, p. 15, 2008, doi: 10.4184/ asj. 2008.2.1.15.

\title{
KHẢO SÁT THỂ TÍCH TUYẾN TIỀN LIÊTT Ở NAM GIỚI TRÊN 45 TUỔI TẠI BỆNH VIỆN ĐẠI HỌC Y HÀ NộI
}

\author{
Nguyễn Hoài Bắc ${ }^{1,2}$, Hạ Hồng Cường², Hoàng Long1
}

\section{TÓM TẮT}

Nghiên cứu được thực hiên trên 2.867 nam giới trên 45 tuổi đến khám tại Khoà Nam học và $Y$ học giới tính bệnh viện Đại học $Y$ Hà Nội nhằm khảo sát thể tích tuyến tiền liệt và mối liên quan giữa thể tích tuyến tiền liệt với các triệu chứng đường tiểu dưới. Kết quả cho thây thể tích tuyến tiền liệt trung bình là $24,2 \mathrm{ml}$. Kích thước tuyến tiền liêt tăng theo tuổi và tăng cao ở nhóm bệnh nhân có triệu chứng đường tiểu dưới. Sau 10 năm thể tích tuyến tiền liệt sẽ tăng lên $4,3 \mathrm{ml}(\mathrm{p}<$ $0,001)$. Mô hình hồi quy logistic đa biến về giá trị dự đoán các triệu chứng đường tiểu của tuổi và thể tích tuyến tiền liệt cho thấy cứ tăng lên $10 \mathrm{ml}$ thể tích tuyến tiền liệt thì: tỷ số khả dĩ $(\mathrm{OR})$ có triệu chứng đường tiểu dưới tăng lên 1,2 lần $(p<0,001)$, tỷ số khả dĩ $(O R)$ có hội chứng kích thích tăng lên 1,2 lần ( $p$ $<0,001)$, tỷ số khả dĩ (OR) có hội chứng tắc nghẽ̃n tăng lên 1,3 lần $(p<0,001)$. Qua nghiên cứu này chúng tôi thấy trên quần thể nam giới trên 45 tuổi đến khám tại bệnh viện Đại học Y Hà Nội thì thể tích tuyến tiền liệt có liên quan với tuổi và các triệu chứng đướng tiểu dưới và thể tích tuyến tiền liệt là một yếu tố độc lập có giá trị dự đoán sự xuất hiện của triệu chứng đường tiểu dưới.

Tư khóa: thể tích tiền liệt tuyến, triệu chứng đường tiểu dưới, u phì đại tuyến tiền liệt.

\section{${ }^{1}$ Trường Đại học Y Hà Nội,}

Bênh viên Đai hơ Y Hà Nôi.

Chịu trách nhiệm chính: Nguyễn Hoài Bắc

Email: nguyenhoaibac@hmu.edu.vn

Ngày nhận bài: 22.10.2020

Ngày phản biện khoa học: 26.11.2020

Ngày duyệt bài: 7.12.2020

\section{SUMMARY \\ CHARACTERISTIC OF PROSTATE VOLUME AND THE RELATIONSHIP WITH LUTS IN MEN UPPER 45 YEARS OLD}

we conducted a study to evaluate the characteristicsof prostate volume on 2,867 man above 45 years old, who visited theAndrology and Sexual Medicine Dept in Hanoi Medical University Hospitalto find out the relationship betwen prostate volume and lower urine tract symptoms. The study showed that the mean prostate volume was $24.2 \mathrm{ml}$, which slightly increased in size (56.4\% of patients ranged from 20 to $40 \mathrm{ml}$ ). For every 10 years, prostate volume increases of $4.3 \mathrm{ml}$. Benign prostate hyperplasia has a considerable effect on the lower urinary tract symptoms in patients who hadprostate volumeabove $40 \mathrm{ml}$. Prostate volume has a predictive value for lower urinary tract symptoms in men over 45 years of age. For every $10 \mathrm{ml}$ increase in prostate volume, the likelihood of lower urinary tract symptoms increased by 1.2 times.

Keyword: prostate volume, lower urinary track symptoms, benign prostate hyperplasia.

\section{I. ĐẶT VẤN ĐỀ}

Tuyến tiền liệt là một trong các tuyến sinh dục phụ của nam giới có nhiệm vụ bài tiết tinh dịch và kháng nguyên đặc hiệu tuyến tiền liệt (PSA). Tiên liệt tuyến được hình thành từ tuần thứ 13 trong thai kì và phát triển dưới tác động của nôi tiết testosterone của cơ thể. Nằm ngay sát cổ bàng quang, ôm quanh đoạn niệu đạo nên tuyến tiền liệt được cho là có liển quan trực 